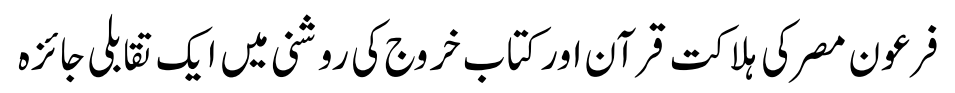

\title{
The Death of Pharaoh in the Light of Holy Quran and Kitaab ul Khorooj (A Comparative Study)
}

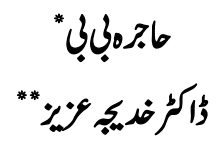

\begin{abstract}
Death of Pharaoh (Firon) is a famous historical event of Banu Israel (descended from Jacob) in the reign of Joseph (Hazrat Yousaf A.S) Banu Israel flourished a lot and they were the most popular sect of the era. Their strength and population was an alarming threat for the kingdom of pharon. So after counseling the mighty king of the time ordered to kill all the boys after taking birth and let the girls survive to be used as maids for the future rulers. Despite this cruel order pharon make the life of Banu Israel hell on earth. To wrap up all this cruelty and bringing the vanity of Pharon to earth Allah sent Moses as Prophet to help Banu Israel.
\end{abstract}

All these incidents are both in Quran and in Torah or kitab ul khorooj. Yet in Khorooj amendments has been made later by Jews. So to clear the concept a comparative analysis has been made that will also help to enhance our knowledge.

Keywords: Pharaoh, banu Israel, kitaab ul Khorooj, Holy Quran, Moses

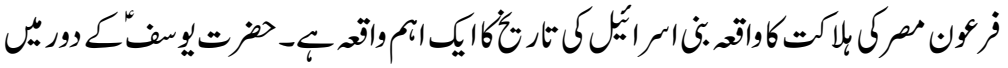

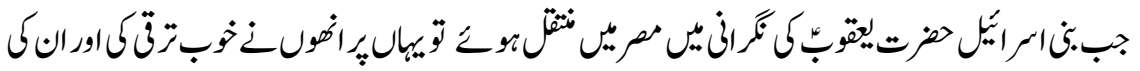

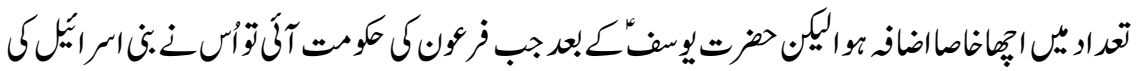

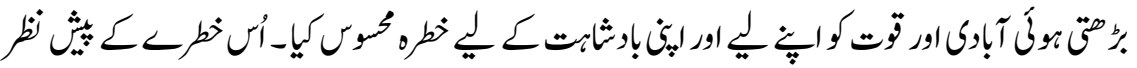

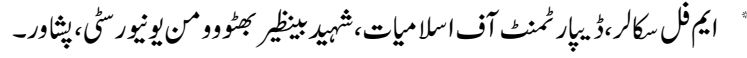

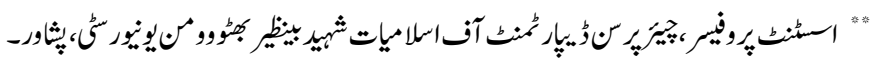




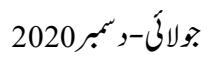

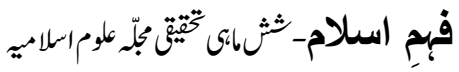

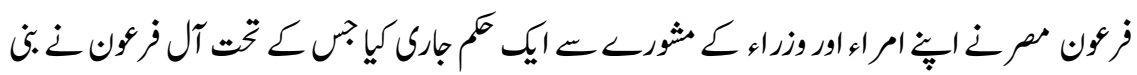

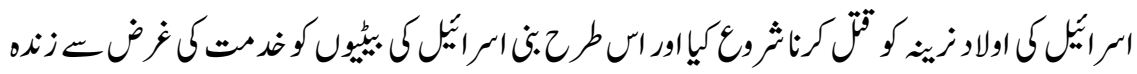

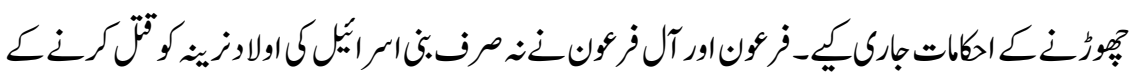

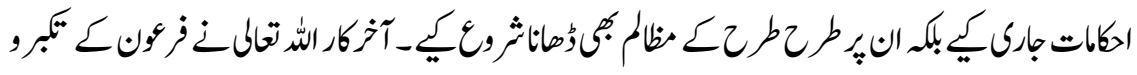

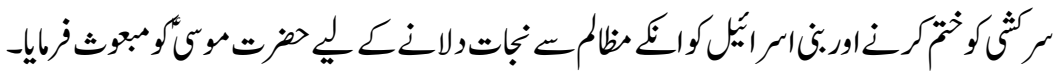

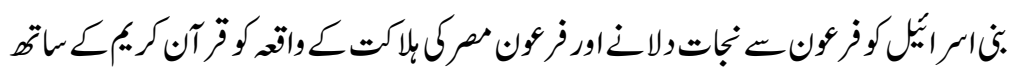

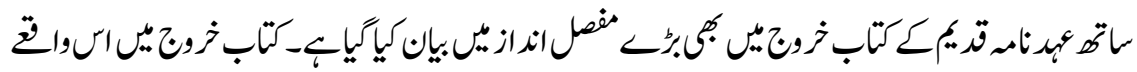

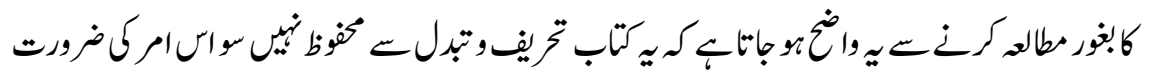

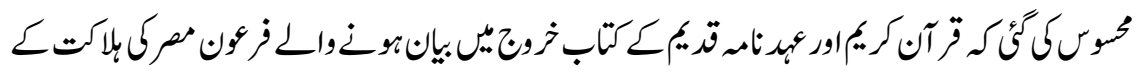

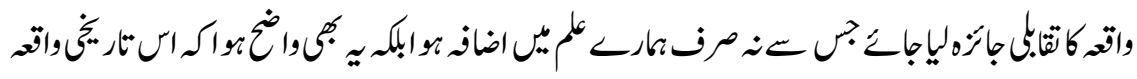

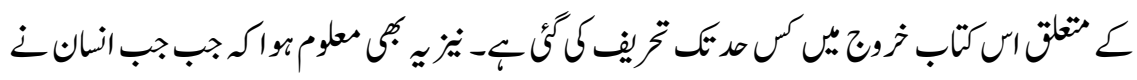

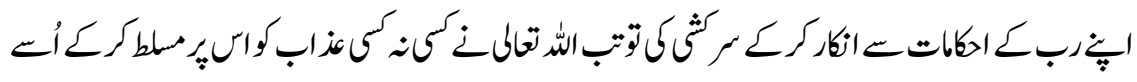

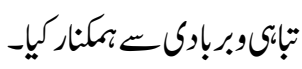

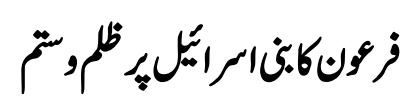

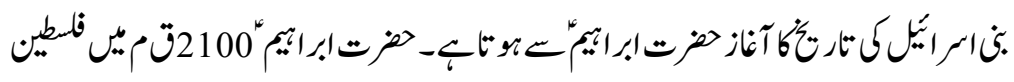

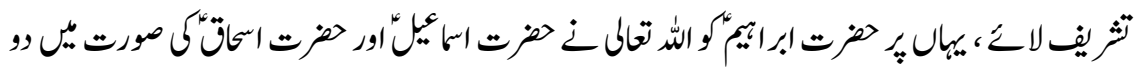

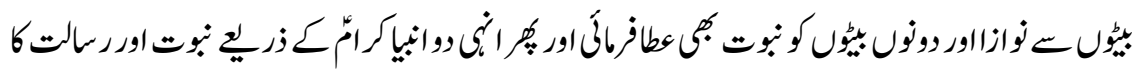

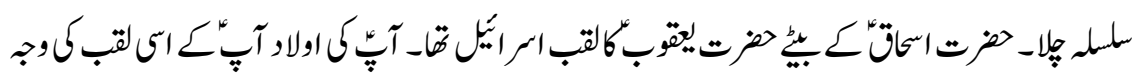

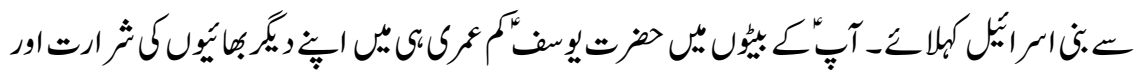

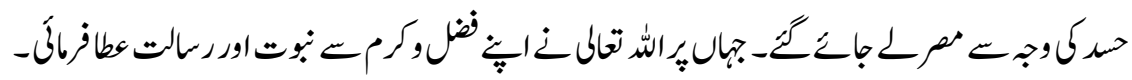

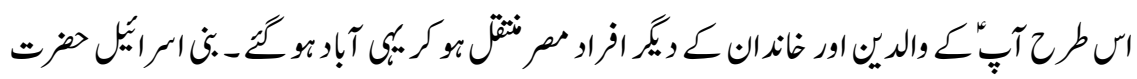

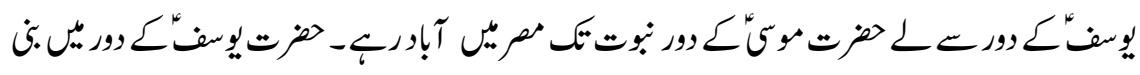

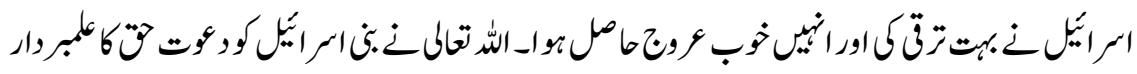

118 


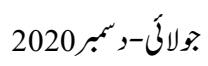

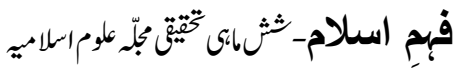

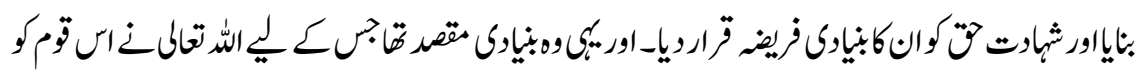

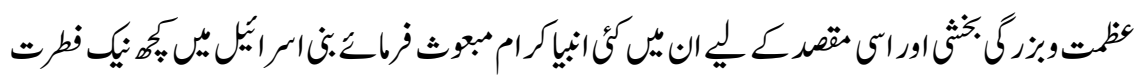

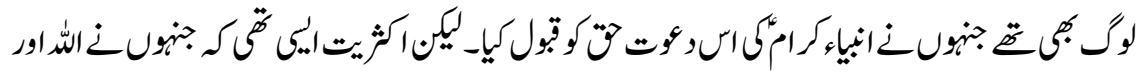

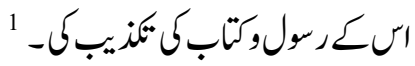

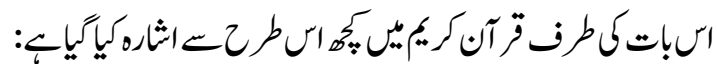

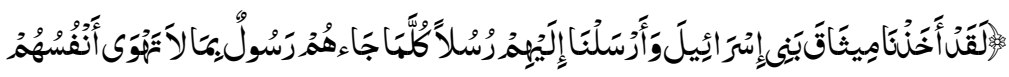

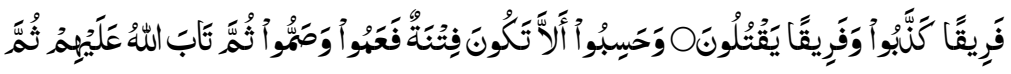

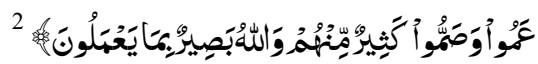

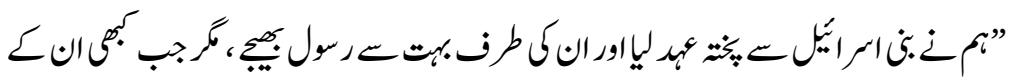

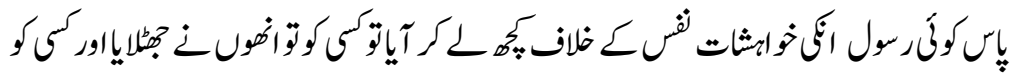

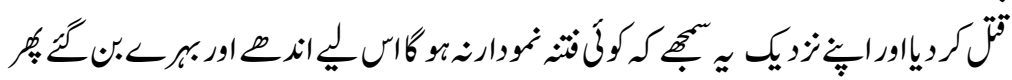

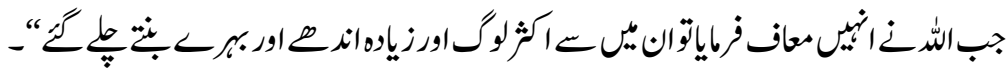

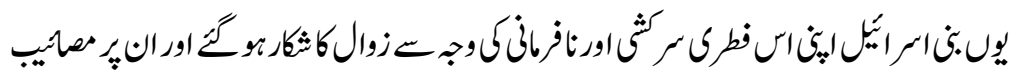

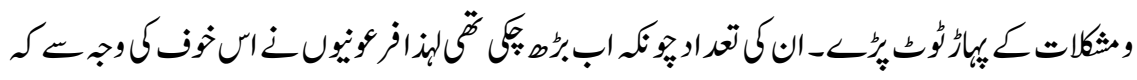

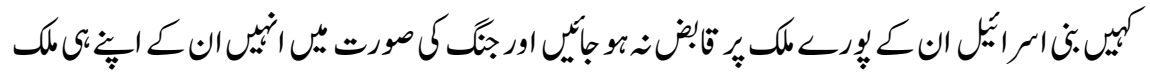

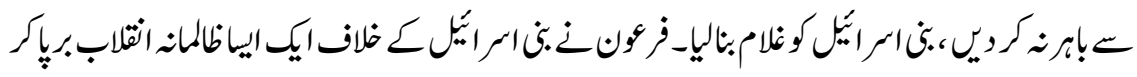

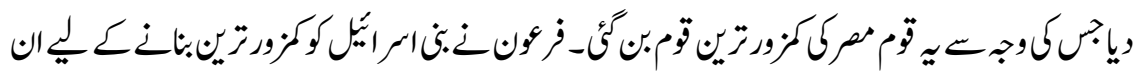

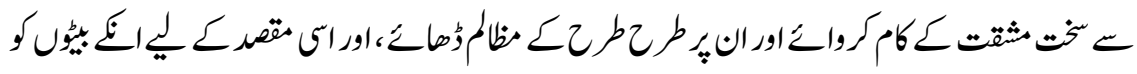

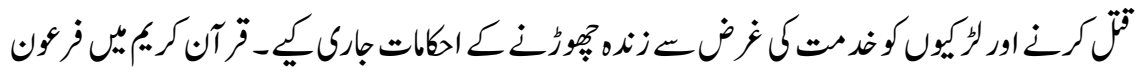

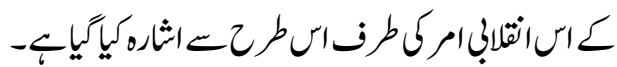

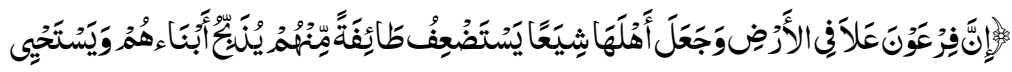

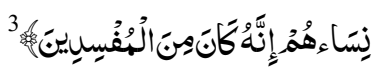

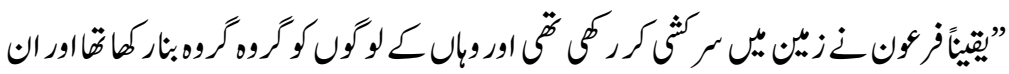

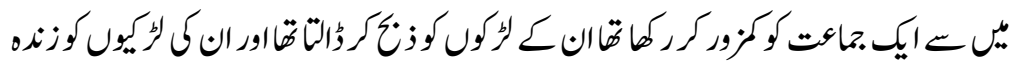

119 


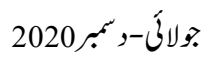

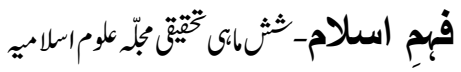

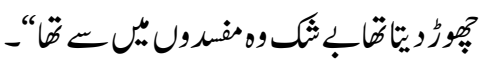

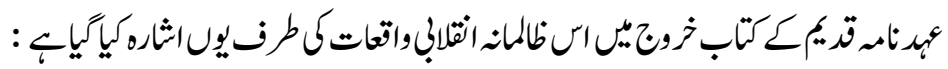

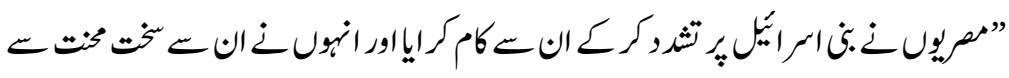

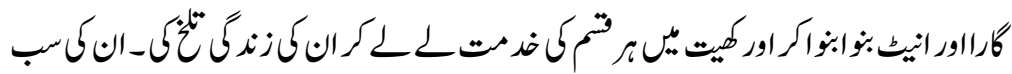

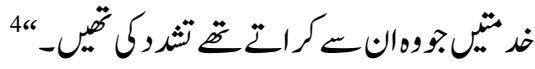

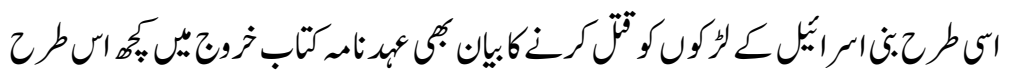

:

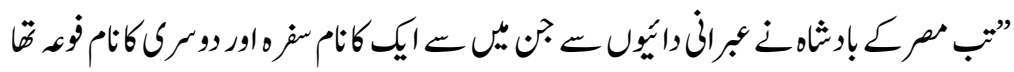

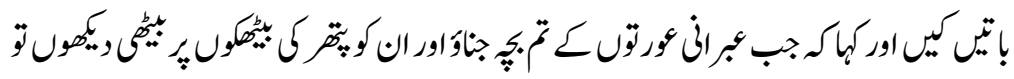

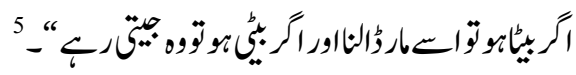

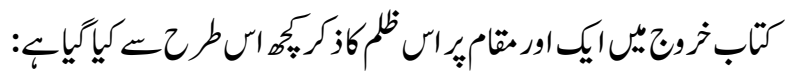

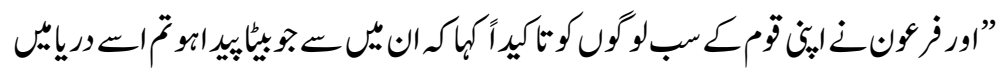

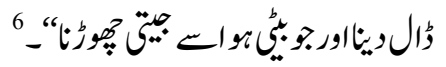

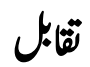

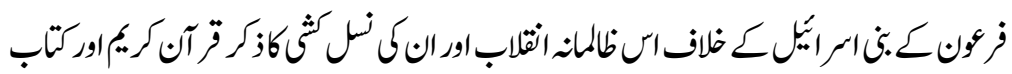

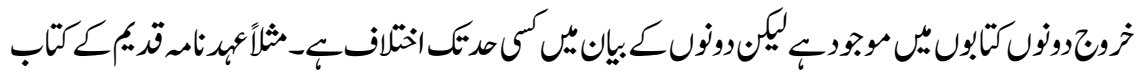

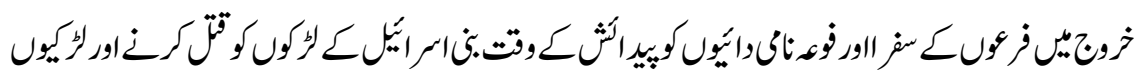

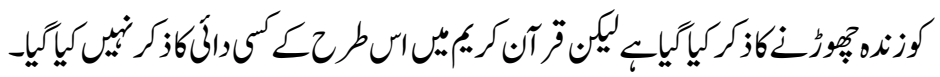

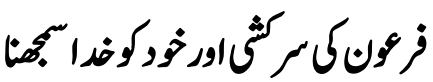

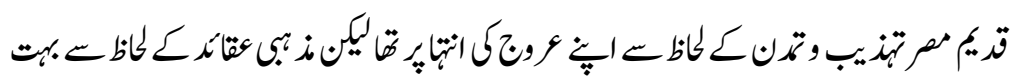

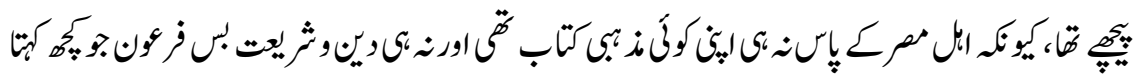

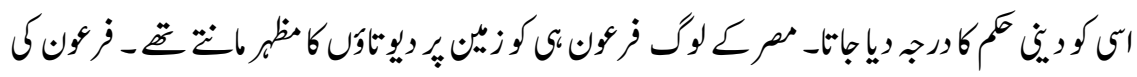

120 


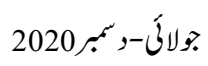

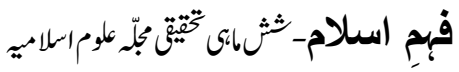

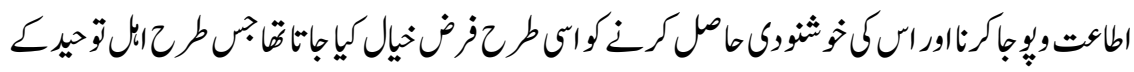

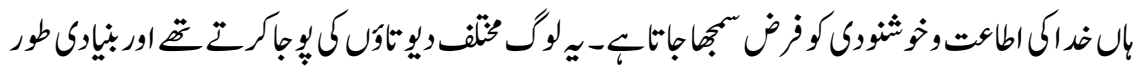

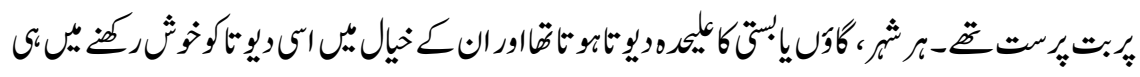

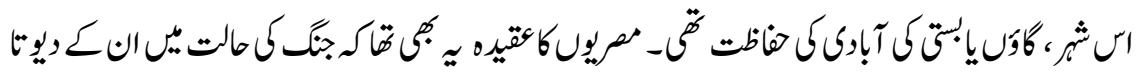

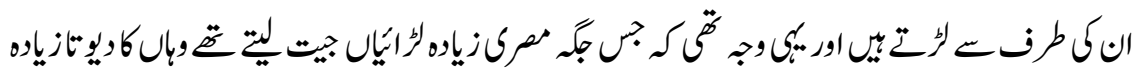

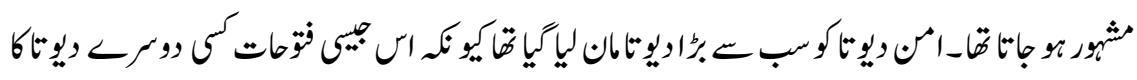

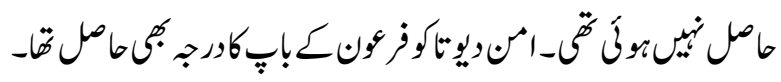

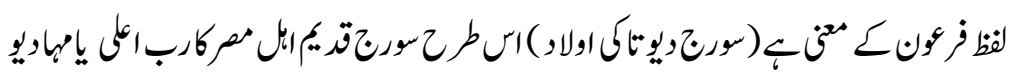

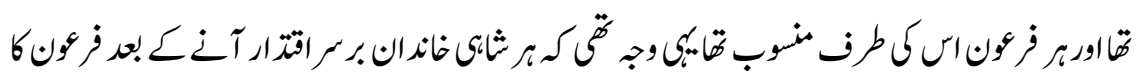

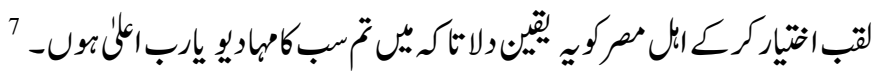

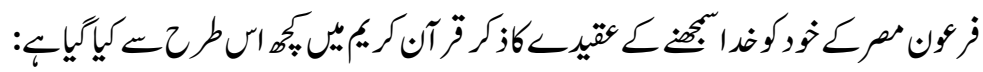

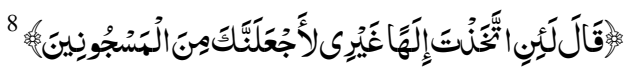

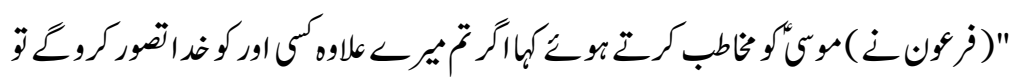

" "

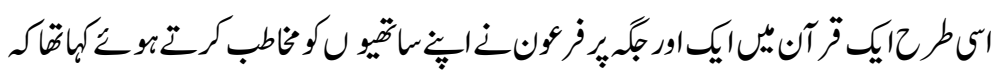

9

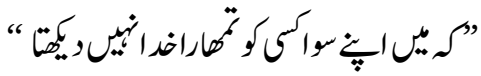

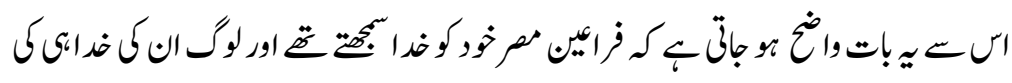

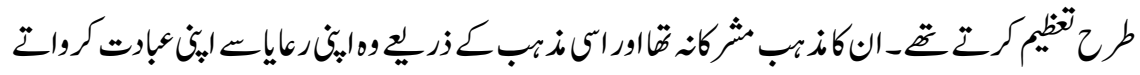

كت

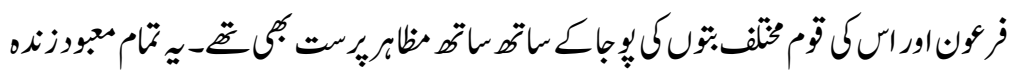

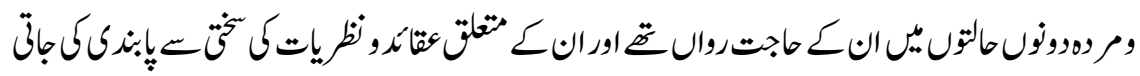

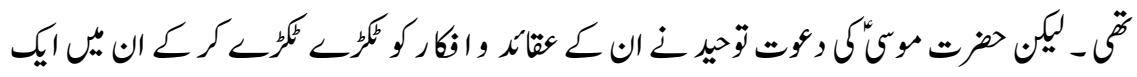

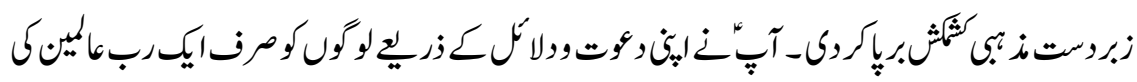

121 


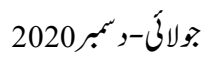

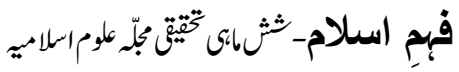

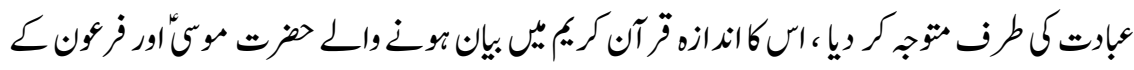

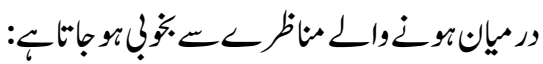

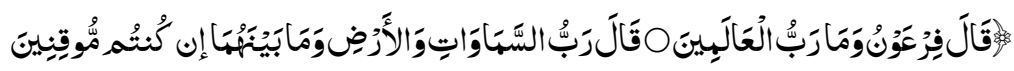

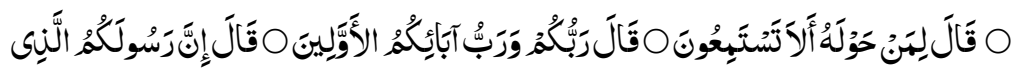

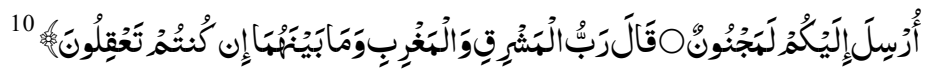

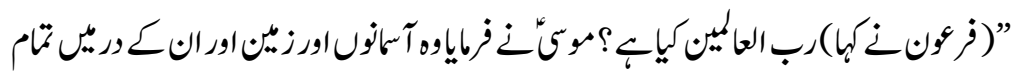

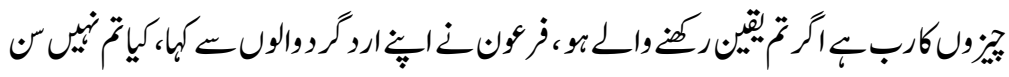

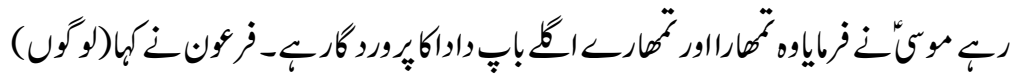

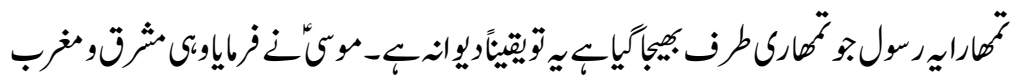

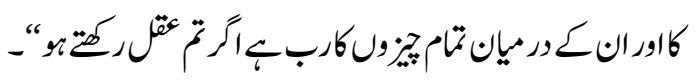

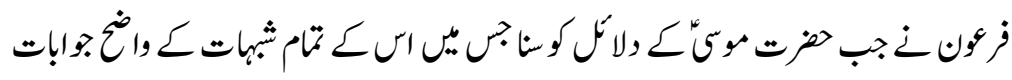

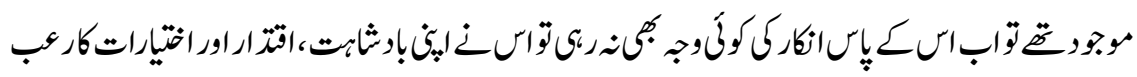

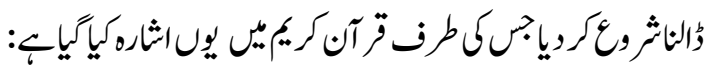

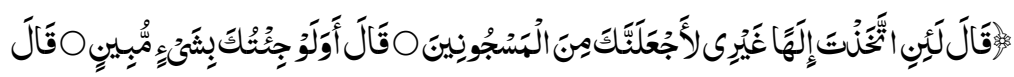

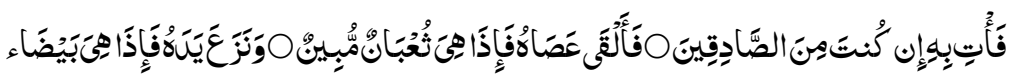

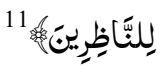

")

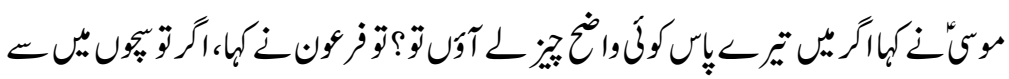

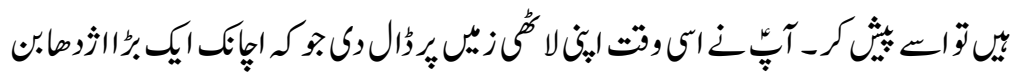

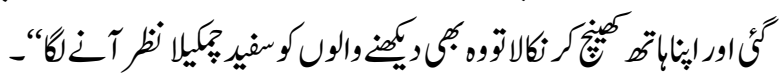

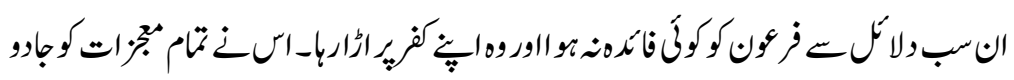

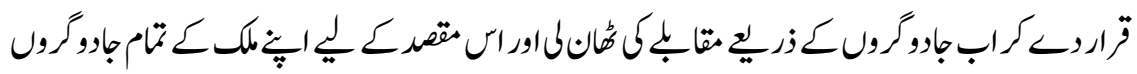

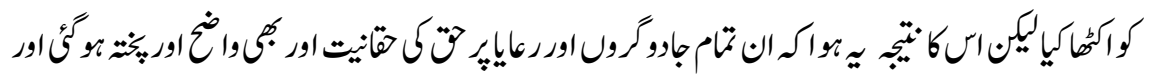

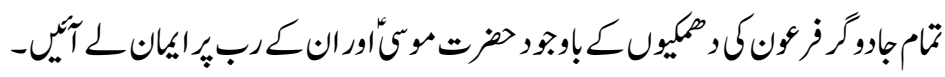

122 


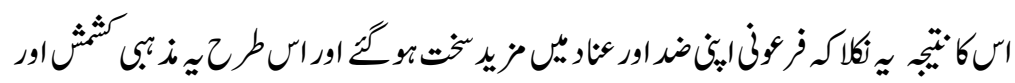

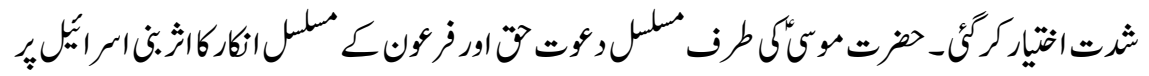

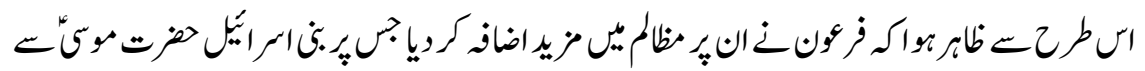

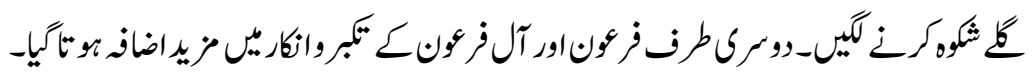

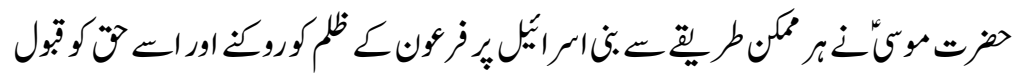

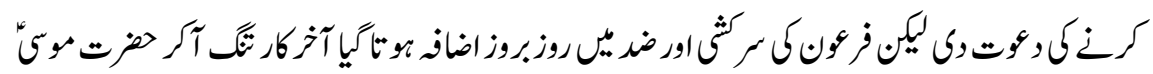

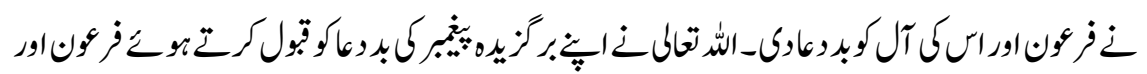

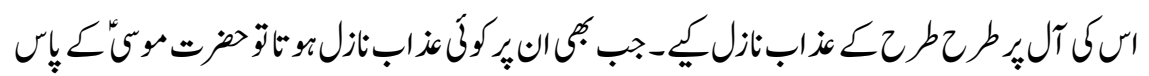

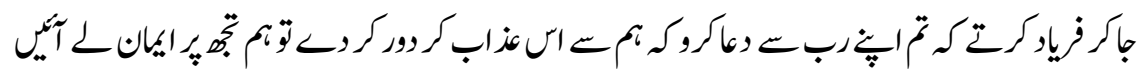

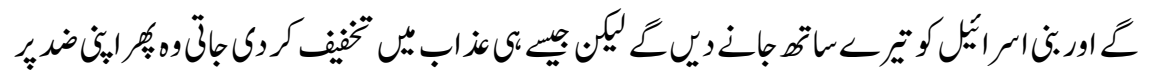

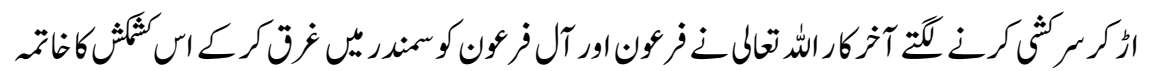

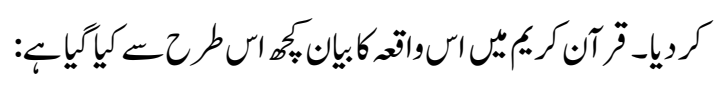

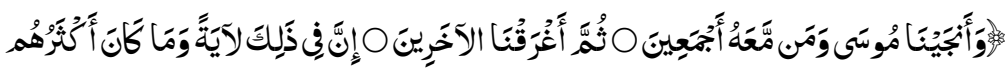

12 مُؤَمْنِينَ

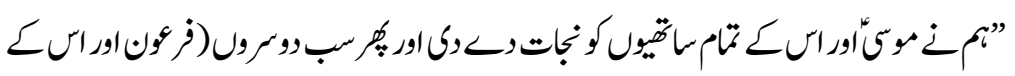

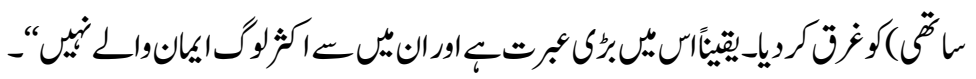

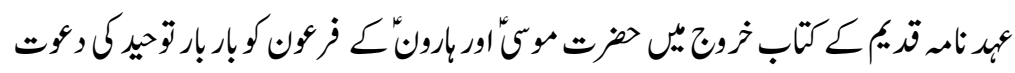

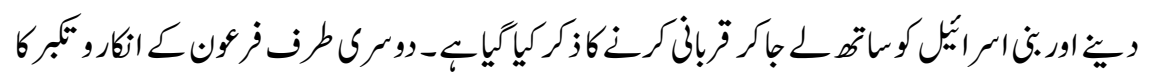

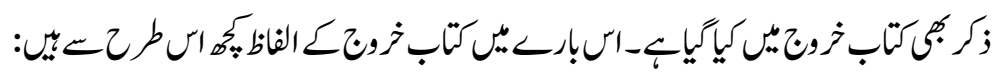

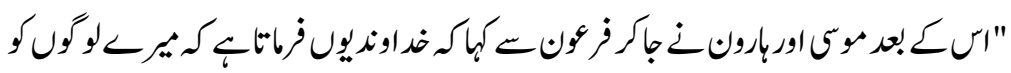

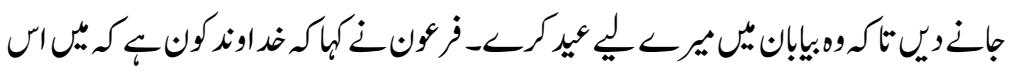




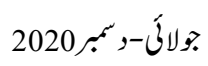

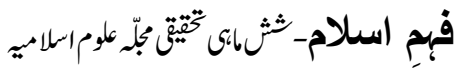

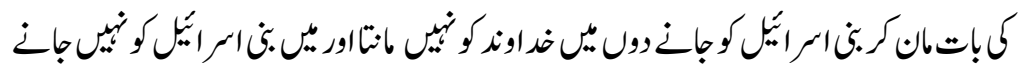

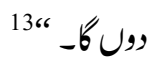

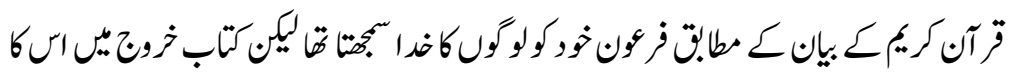

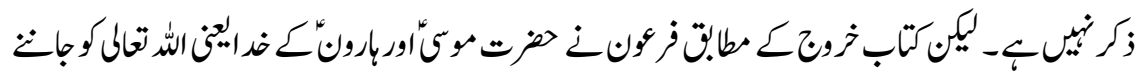

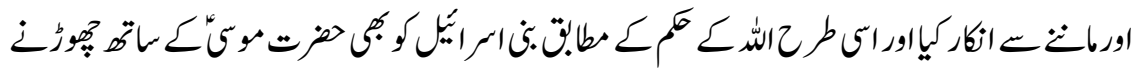

ع انكركيا-

; ;

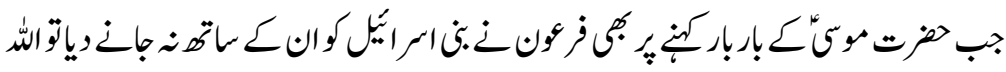

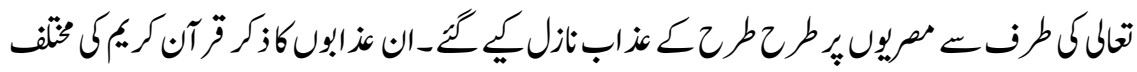

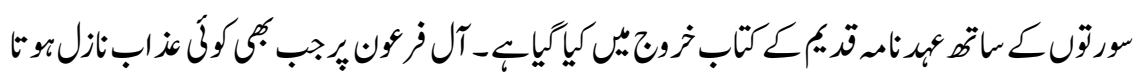

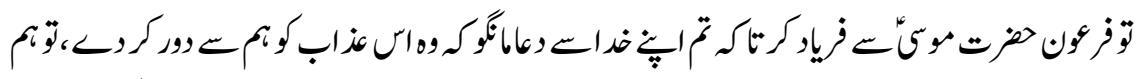

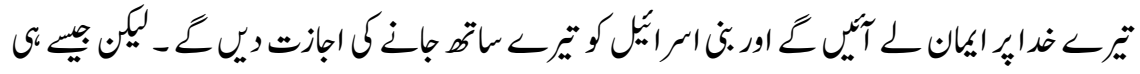

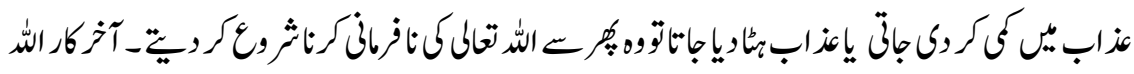

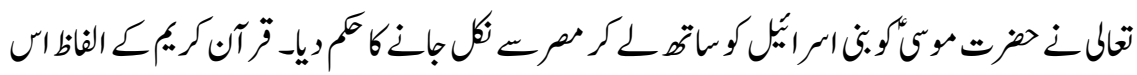

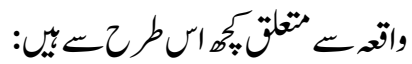

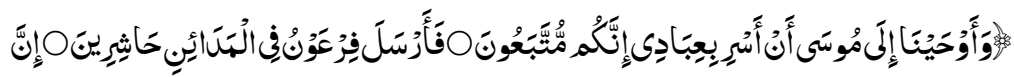

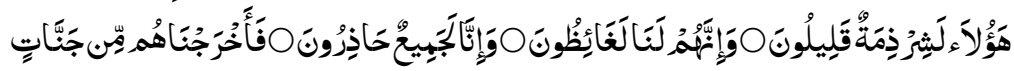

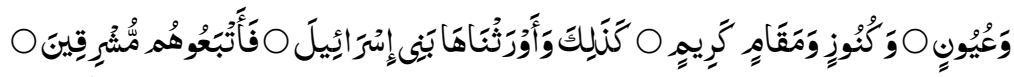

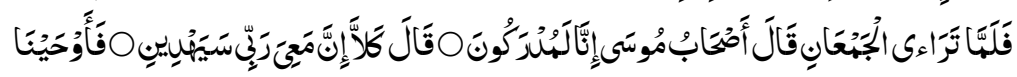

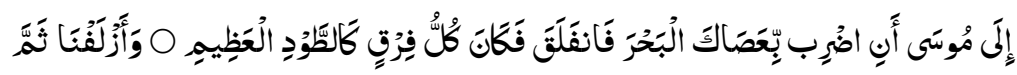

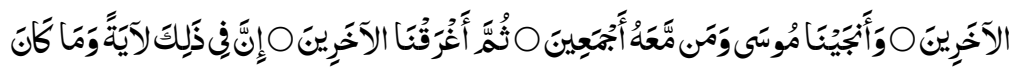

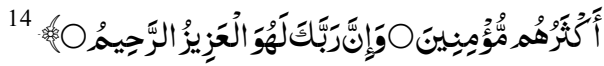

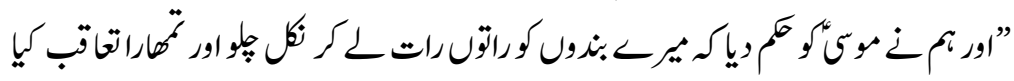

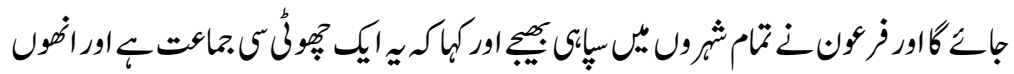

124 


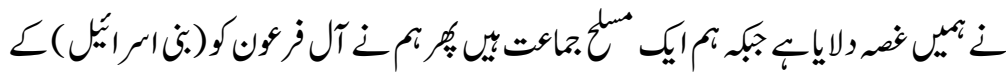

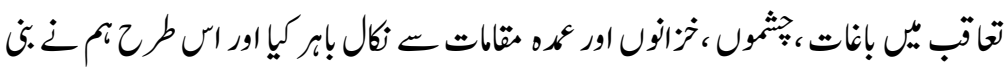

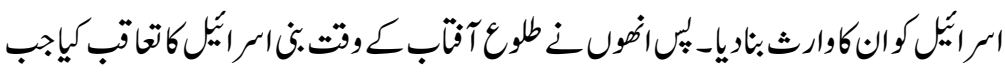

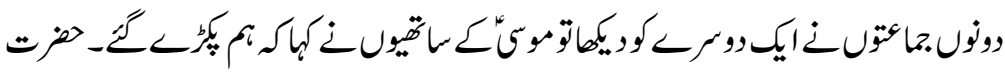

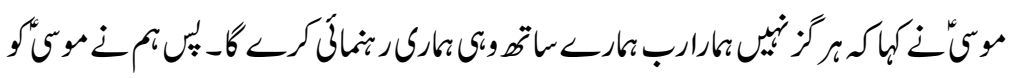

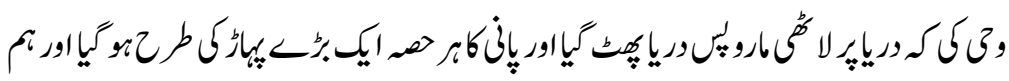

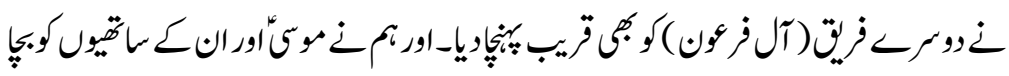

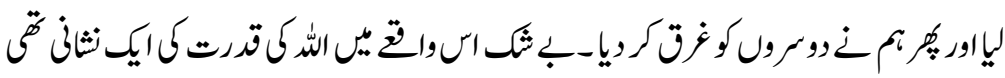

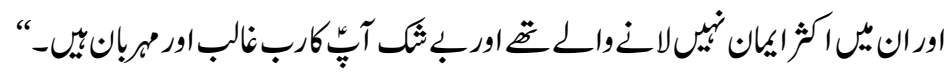

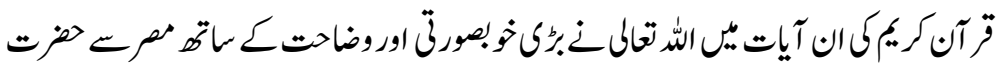

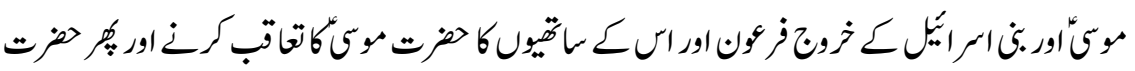

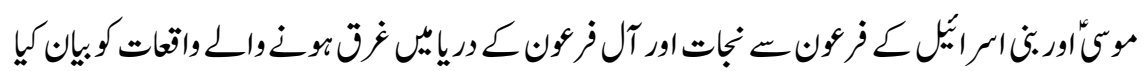

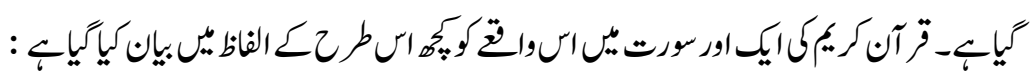

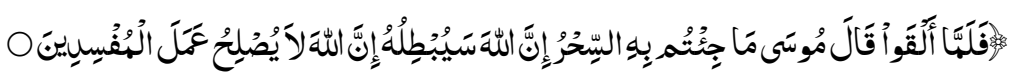

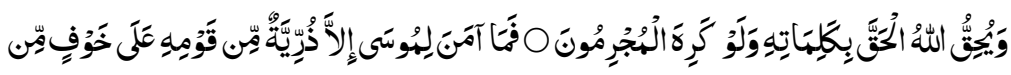

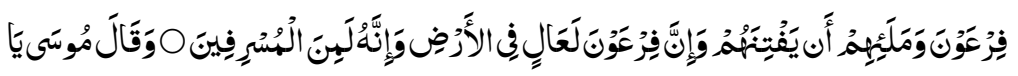

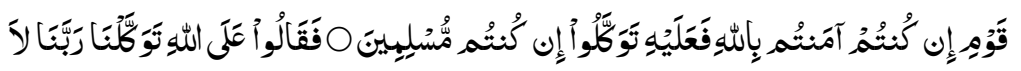

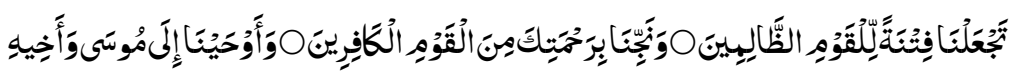

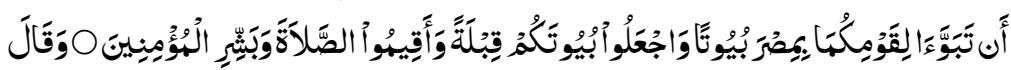

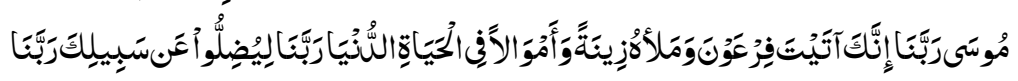

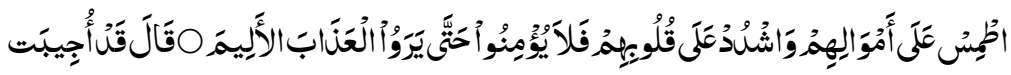

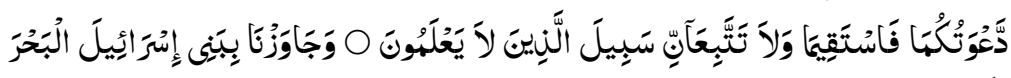

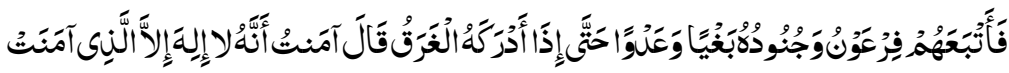

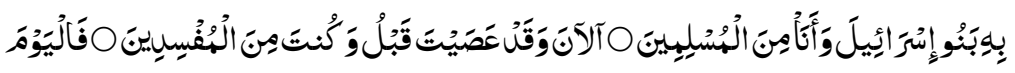
${ }^{15} 15$ 


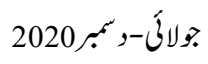

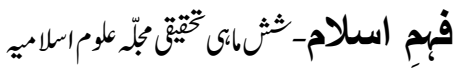

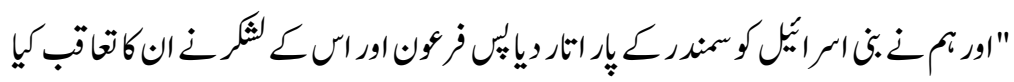

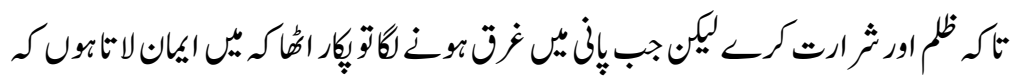

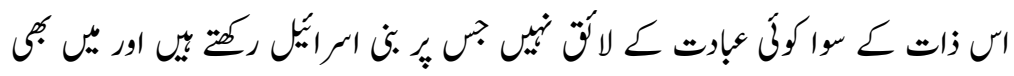

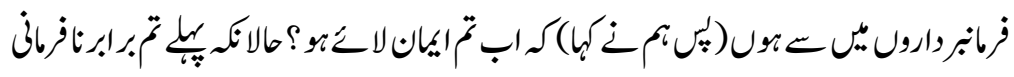

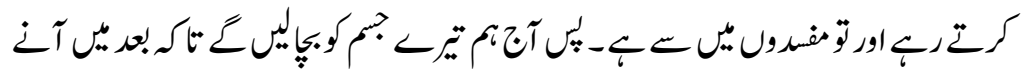

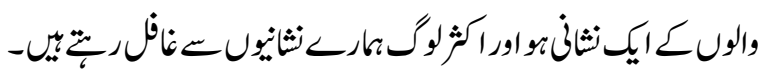

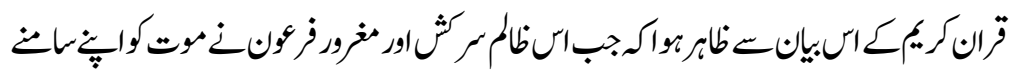

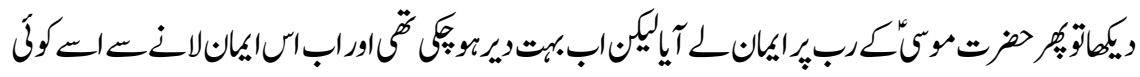

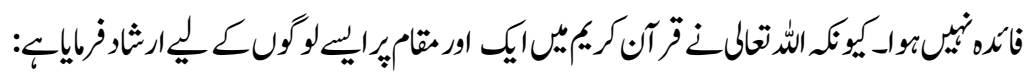

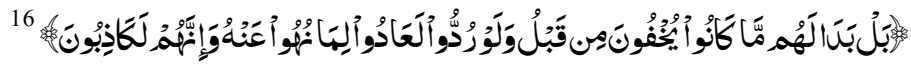

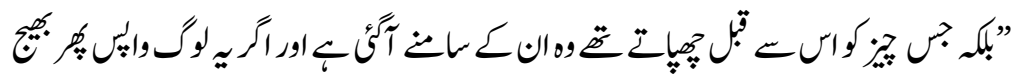

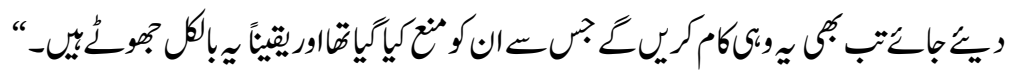

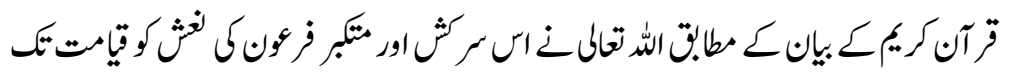

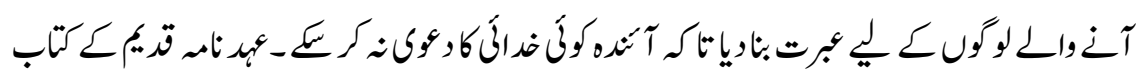

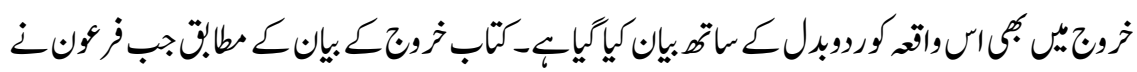

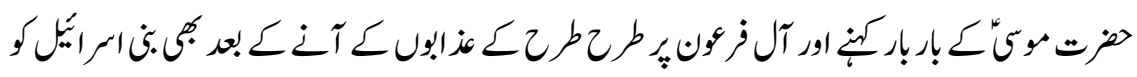

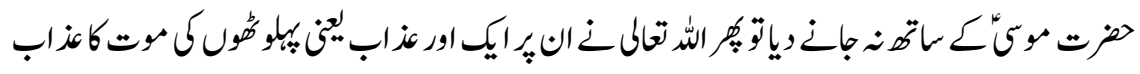

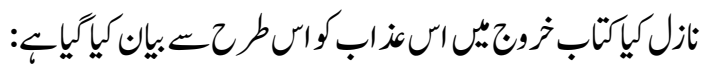

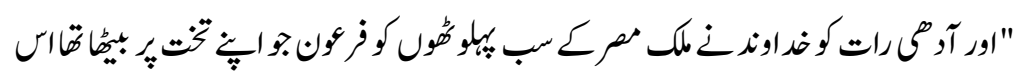

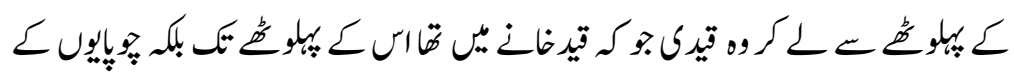

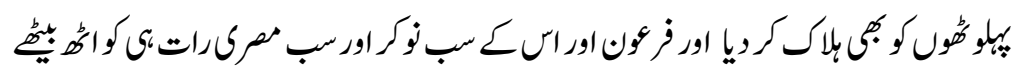

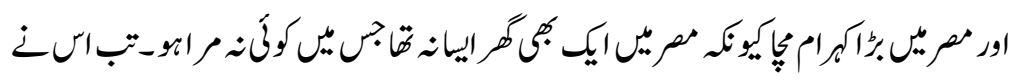

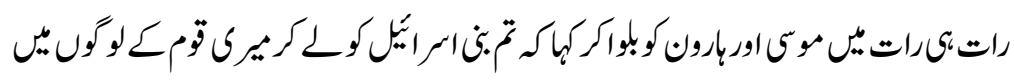

126 


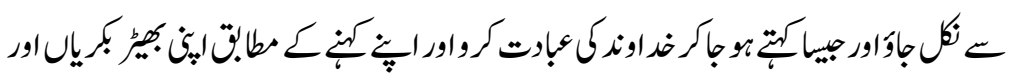

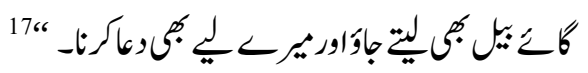

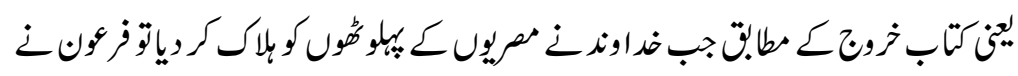

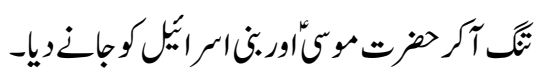

ت*t:

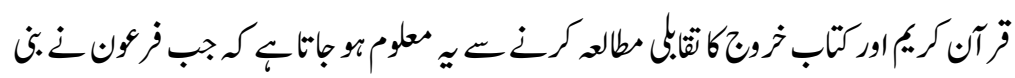

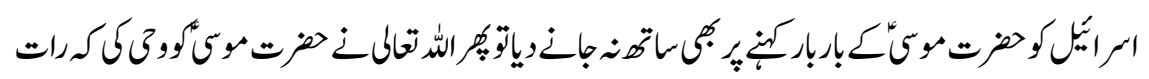

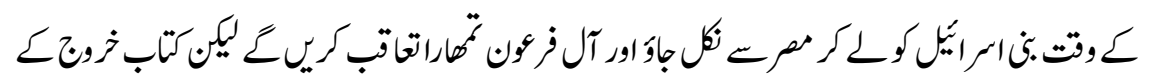

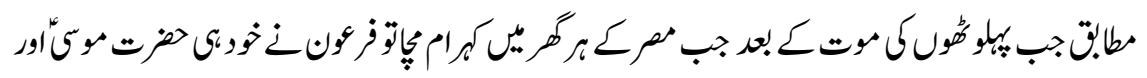

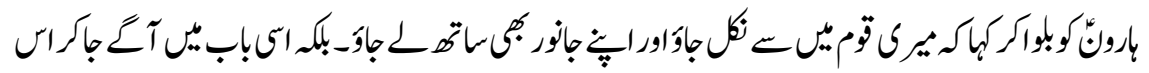

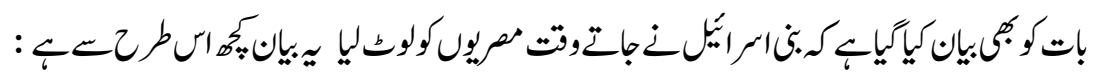

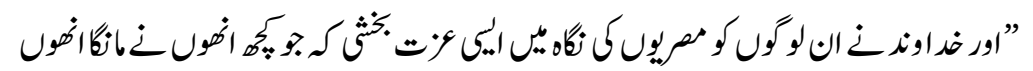

$$
\text { ند }
$$

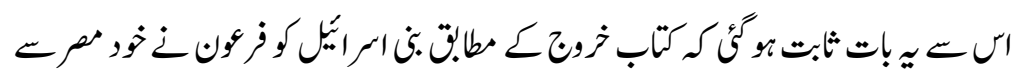

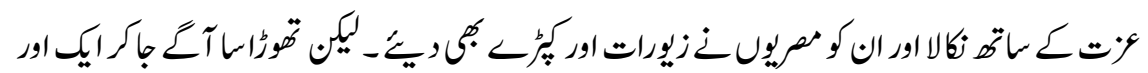

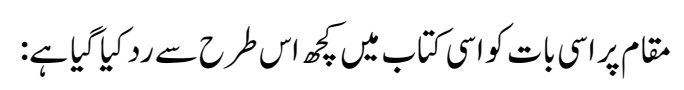

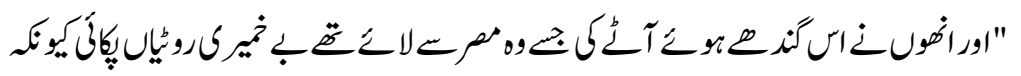

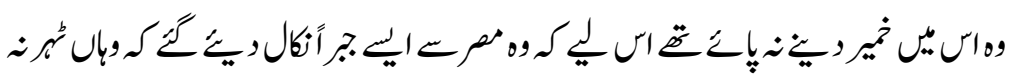

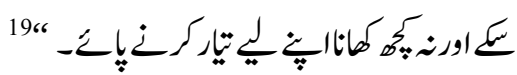

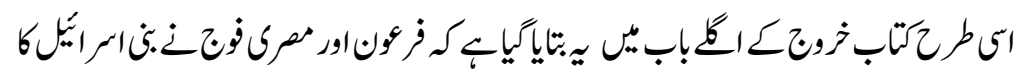

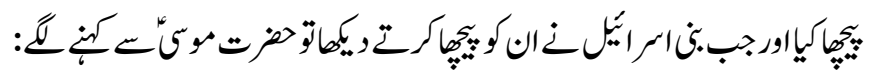




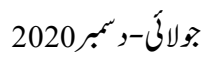

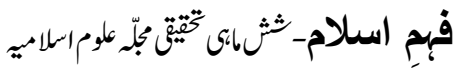

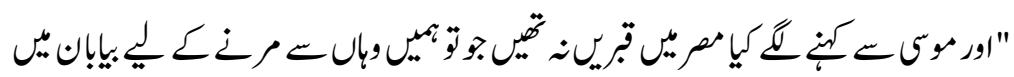

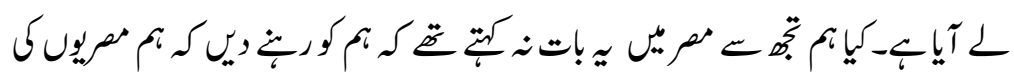

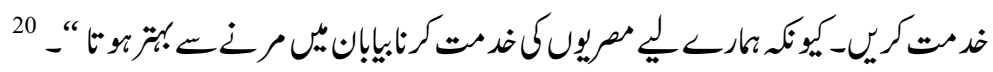

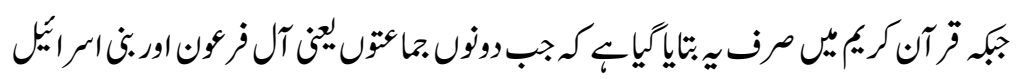

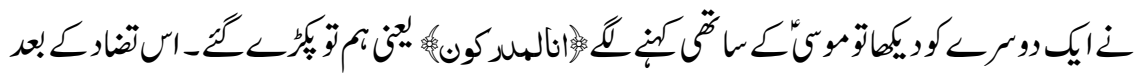

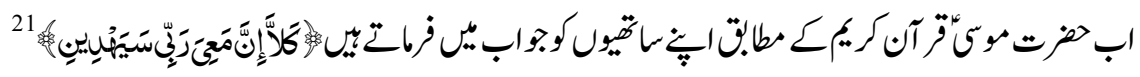

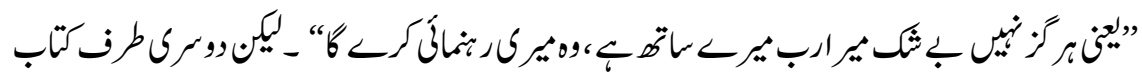

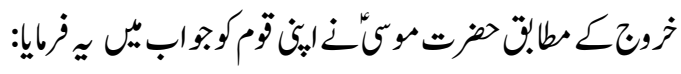

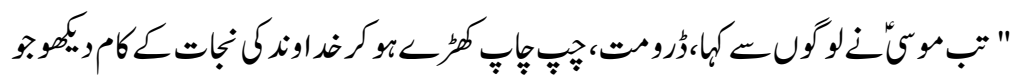

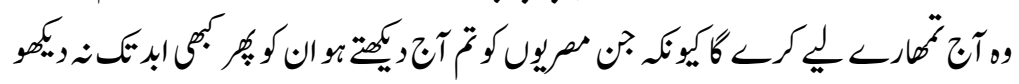

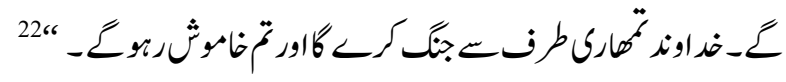

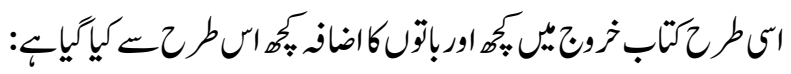

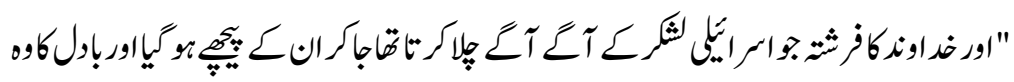

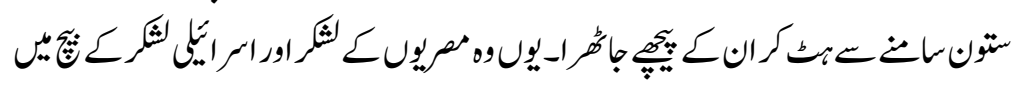

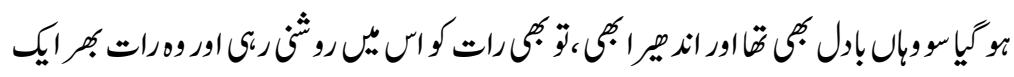

23 " 23

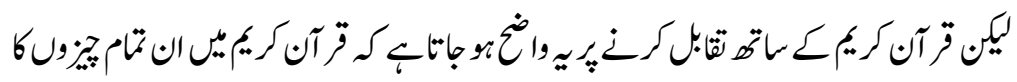

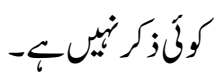

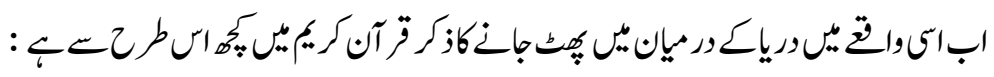

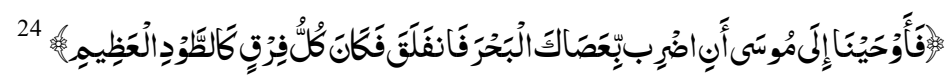

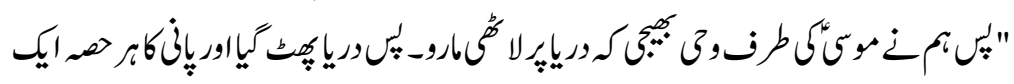

“"

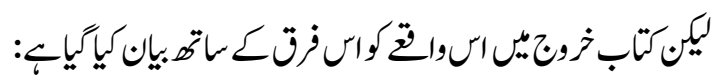

128 


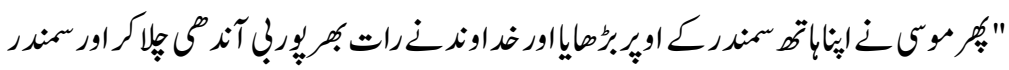

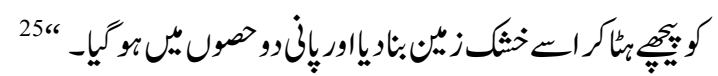

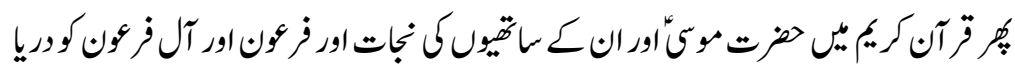

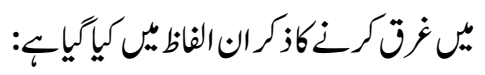
26 " 26

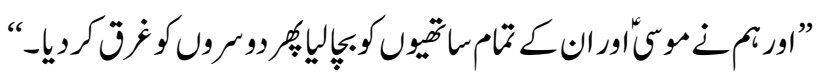

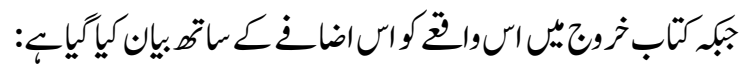

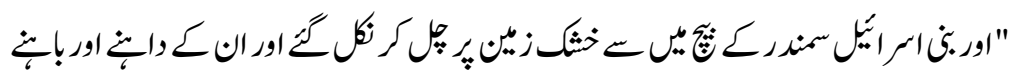

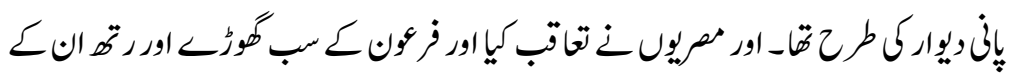

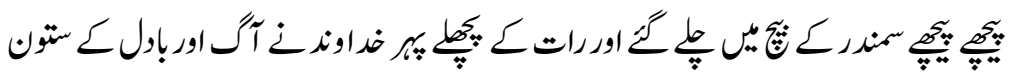

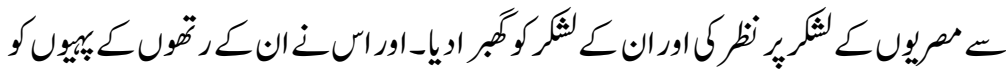

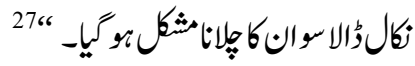

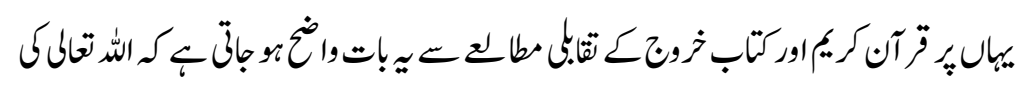

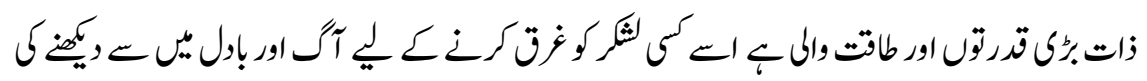

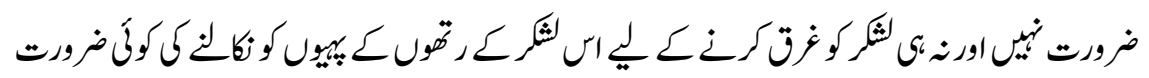

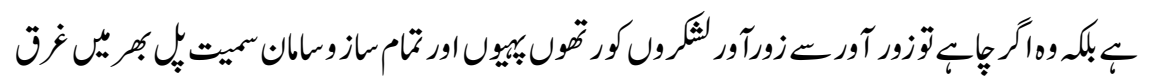

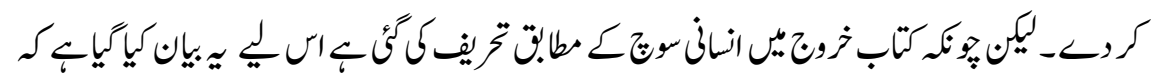

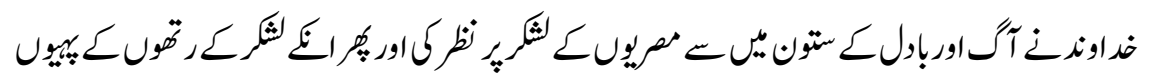

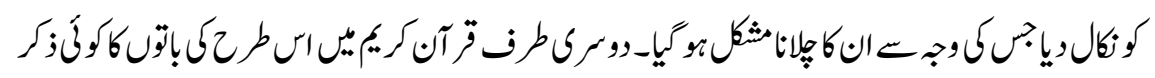

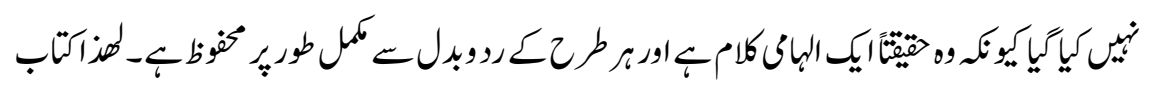

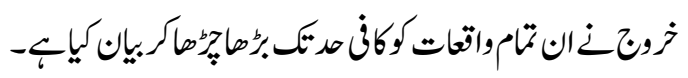




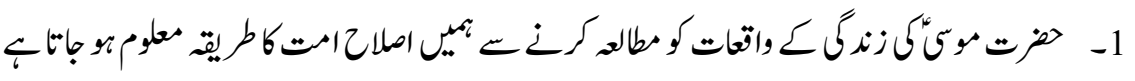

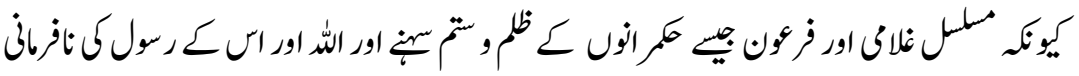

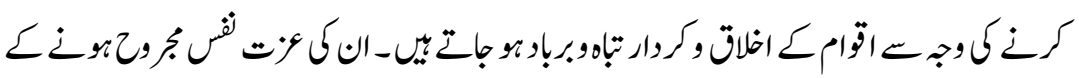

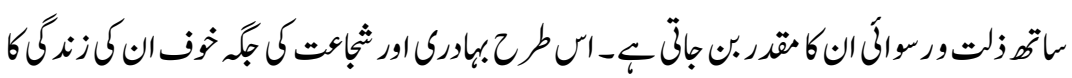

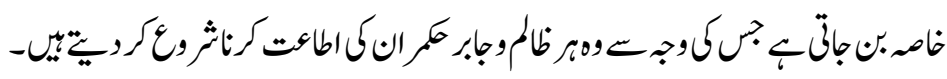

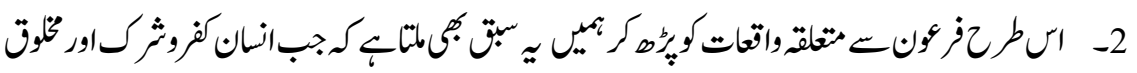

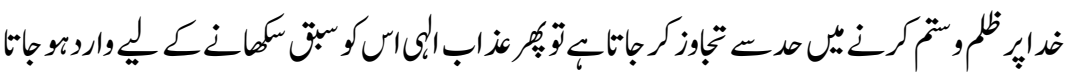

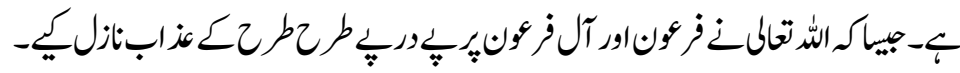

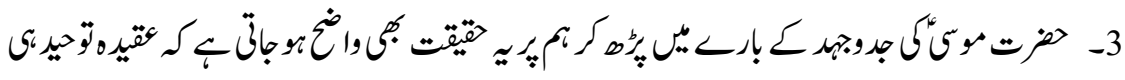

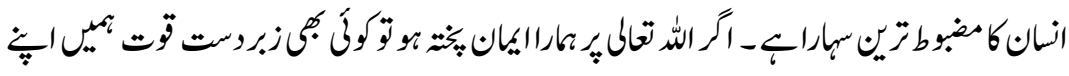

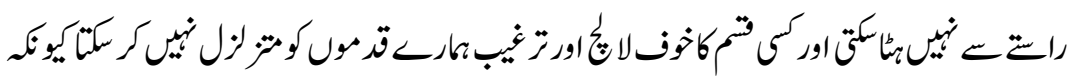

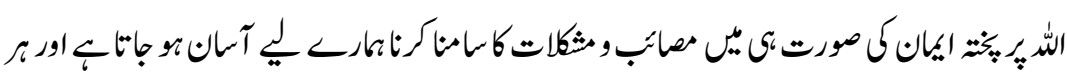

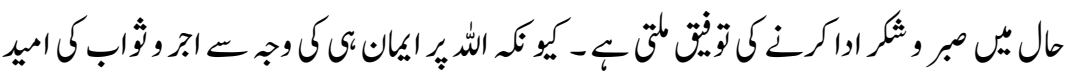

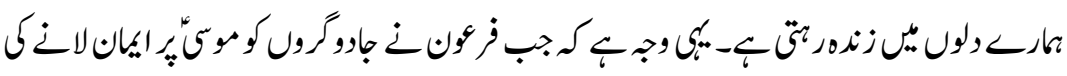

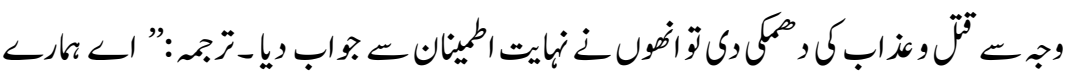

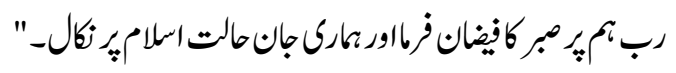

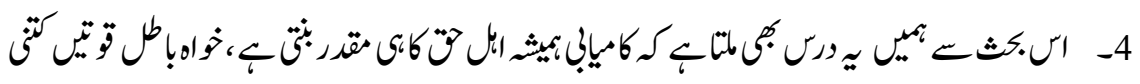

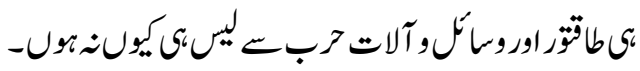

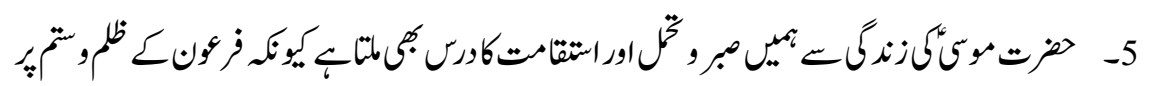

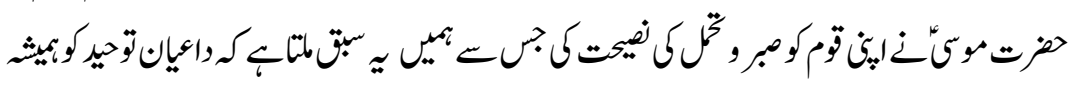




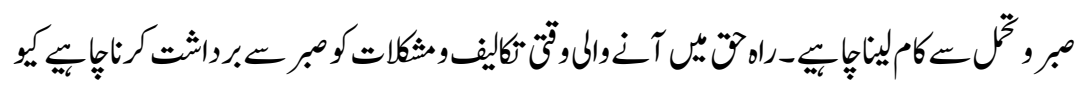

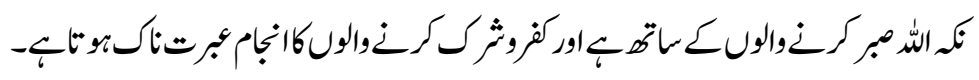

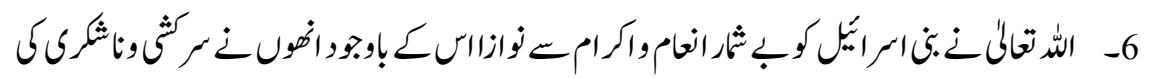

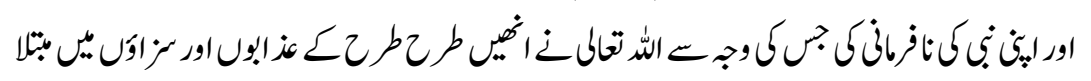

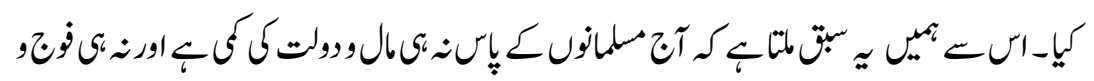

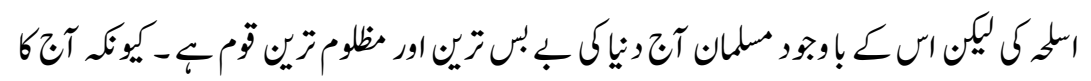

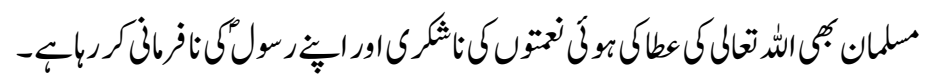

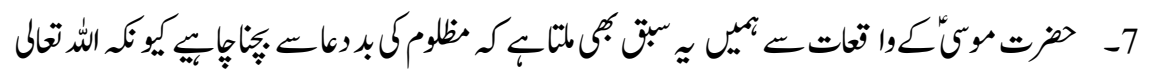

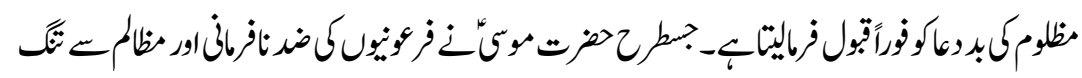

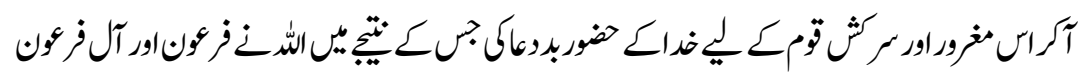

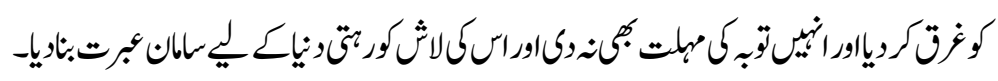

\section{حوالد جإ}

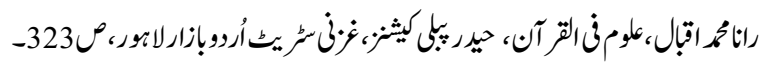

$$
\begin{aligned}
& 2 \\
& 3
\end{aligned}
$$

4

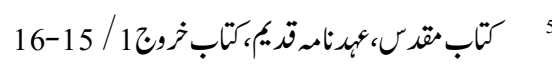

$$
622 \text { ك } 22
$$

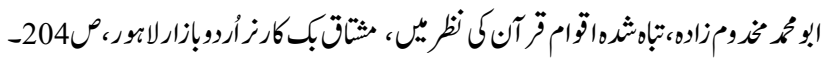

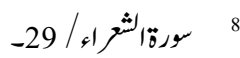

$$
\begin{aligned}
& 9 \text { بورة/القصص/ 3- } \\
& 10 \text { سورةاشثراء/23-28 } \\
& 11 \text { سورةاشثراء/29-33- }
\end{aligned}
$$




$$
\begin{aligned}
& 12
\end{aligned}
$$

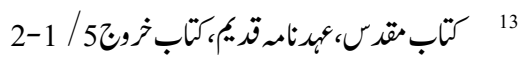

$$
\begin{aligned}
& 14 \\
& 15 \text { سورةليونى/ } 150 \\
& 16
\end{aligned}
$$

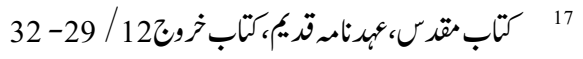

$$
\begin{aligned}
& 18
\end{aligned}
$$

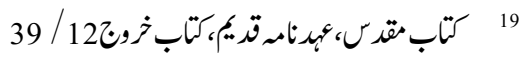

$$
\begin{aligned}
& 20 \\
& 21 \\
& 22
\end{aligned}
$$

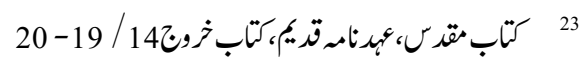

$$
\begin{aligned}
& 24
\end{aligned}
$$

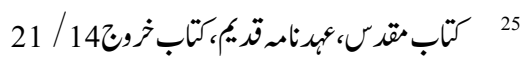

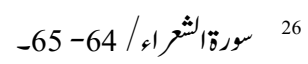

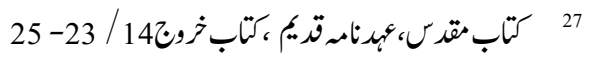

